\title{
The Effect of Co-feeding Methyl Acetate on the H-ZSM5 Catalysed Methanol-to-Hydrocarbons Reaction
}

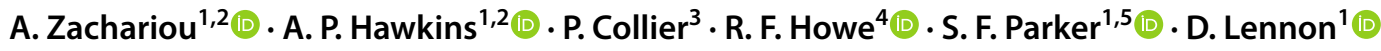

Published online: 3 April 2020

(c) The Author(s) 2020

\begin{abstract}
The reactivity of methanol and methyl acetate mixtures over a HZSM-5 catalyst is studied over a period of $6 \mathrm{~h}$ at $350{ }^{\circ} \mathrm{C}$, with small molecular weight olefins and aromatic compounds observed as reaction products. Post-reaction analysis of the catalyst shows the coke content to increase with methyl acetate content. Vibrational spectra (DRIFTS and inelastic neutron scattering, INS) indicate the major hydrocarbon species present in the coked catalysts to be methylated aromatic molecules, with INS spectra indicating a greater degree of methylation in the catalysts used with higher methyl acetate content. The greater extent of deactivation at higher methyl acetate concentrations is tentatively attributed to a diminishment of water in the zeolite cavity, which would otherwise facilitate re-generation of the active sites.
\end{abstract}

Keywords HZSM-5 · Methanol-to-hydrocarbons reaction · Methyl acetate $\cdot$ Inelastic neutron scattering

\section{Introduction}

The methanol-to-hydrocarbons reaction (MTH) provides a catalytic route where methanol, a relatively cheap feedstock, can be turned into more valuable and industrially relevant products. The MTH reaction uses an acidic zeolite catalyst, commonly ZSM-5, which can produce light olefins and a range of methylated aromatics [1]. The catalyst at steadystate is thought to operate via a 'hydrocarbon pool' (HCP) mechanism. The HCP mechanism is an autocatalytic cycle that describes how the catalyst functions after the first hydrocarbons have formed $[2,3]$. However, the mechanism of

$\triangle$ D. Lennon

David.Lennon@glasgow.ac.uk

1 School of Chemistry, University of Glasgow, Joseph Black Building, Glasgow G12 8QQ, UK

2 UK Catalysis Hub, Research Complex at Harwell, STFC Rutherford Appleton Laboratory, Chilton, Oxon OX11 0FA, UK

3 Johnson Matthey Technology Centre, Blounts Court, Sonning Common, Reading RG4 9NH, UK

4 Department of Chemistry, University of Aberdeen, Aberdeen AB24 3UE, UK

5 ISIS Facility, STFC Rutherford Appleton Laboratory, Chilton, Oxon OX11 0QX, UK formation of the first carbon-carbon bonds is still elusive, with many different proposals in the literature [4].

Understanding how the first $\mathrm{C}-\mathrm{C}$ bonds are created may help optimisation of catalyst composition in order to both maximise efficiency but also tune selectivity. One recent proposal independently reported by the groups of Lercher [5] and Weckhuysen [6] is that carbon-carbon bonds are created via methyl acetate (MeOAc) as the first intermediate. $[5,6]$. Formation of MeOAc from methanol or dimethylether (DME) requires the feedstock to undergo a carbonylation reaction, which forms surface acetate groups. The carbonylation reaction also requires a source of $\mathrm{CO}$, which Lercher et al. suggest may result from dehydrogenation of methanol [5]. Methanol and DME carbonylation to form MeOAc has been reported mainly with a mordenite acid zeolite catalyst, although good selectivity towards $\mathrm{MeOAc}$ at relatively lower temperatures has also been observed with HZSM-5 [7, 8]. $\mathrm{CO}$ has also been observed as part of the initial stages of the MTH reaction, both on ZSM-5 and on SAPO-34 [9, 10]. In studies where the carbonylation reaction was the main focus, it has been reported that water causes the carbonylation rate to decrease due to competitive adsorption with the $\mathrm{CO}$, since methanol is dehydrated to form DME and water, the carbonylation step is expected to be the rate limiting step of the MTH reaction [7, 11].

In this study we have explored the reactivity of methanol-MeOAc mixtures over an HZSM-5 catalyst at 
temperatures representative of that employed in $\mathrm{MTH}$ chemistry. We particularly focus on the effects of MeOAc on the catalyst lifetime, employing inelastic neutron scattering spectroscopy (INS) to characterise the used catalysts. INS has considerable potential for investigating zeolite catalysts as it provides access to the vibrational spectra of used catalysts over a wide frequency range without obstruction from zeolite lattice modes [12]. We have recently reported the use of INS to study HZSM-5 catalysts used in the MTH reaction $[13,14]$ and the role of DME in the $\mathrm{MTH}$ reaction chemistry [15].

In the present work we examine the MTH reaction for a period of $6 \mathrm{~h}$ at $350{ }^{\circ} \mathrm{C}$ in the presence of different amounts of MeOAc. The reaction was monitored by in-line mass spectrometry whilst, additionally, liquid products were collected in a catch-pot and analysed by GC-MS. Post-reaction, the catalyst samples were analysed by INS, $\mathrm{N}_{2}$ sorption experiments and temperature programmed oxidation (TPO).

\section{Experimental}

The HZSM-5 (Si:Al ratio=30) zeolite used is a commercially available catalyst provided in powder form by Johnson Matthey plc. Catalyst characterisation has been reported elsewhere [13]. Residual HZSM-5 template (tetrapropyl ammonium bromide) was removed by heating the zeolite in air at $500{ }^{\circ} \mathrm{C}$ for $12 \mathrm{~h}$ prior to use.

\subsection{Reaction Testing}

The reactions were conducted using a reaction test facility located in the ISIS Neutron and Muon Source that is described in detail by Warringham et al. [16]. The fixed bed reactor is made of stainless steel with an internal diameter of $35 \mathrm{~mm}$ and length of $60 \mathrm{~cm} .12 \mathrm{~g}$ of calcined HZSM-5 were loaded on the reactor and dried under a constant flow of $\mathrm{He}\left(150 \mathrm{ml} \mathrm{min}^{-1}, \mathrm{CK}\right.$ gas, $\left.>99 \%\right)$ at $350{ }^{\circ} \mathrm{C}$ for $3 \mathrm{~h}$. After the drying process, the reactor is kept at temperature and the reactant feed was introduced into the reactor at a rate of 1 $g_{\text {reactant }} g_{\text {catalyst }}^{-1} h^{-1}$. The reactant feed was a liquid mixture of methanol and methyl acetate (with molar percentages of $0 \% \mathrm{MeOAc}, 10 \% \mathrm{MeOAc}, 30 \% \mathrm{MeOAc}, 60 \% \mathrm{MeOAc}$ and $100 \% \mathrm{MeOAc}$ ) and all reactions were stopped after $6 \mathrm{~h}$. The reactor was then flushed for $15 \mathrm{~min}$ with helium to remove any excess reactant feed present before being isolated and allowed to cool to ambient temperature.

\subsection{Product Analysis}

Gaseous products were analysed by in-line mass spectrometry (Hiden Analytical, HPR-20) connected to the exit line of the reactor via a differentially-pumped heated quartz capillary. A catch-pot placed downstream of the reactor was used to collect liquid products. They were analysed by off-line GC-MS (Agilent 7890A GC, 5975 MSD, DB-1MS capillary l: $60 \mathrm{~m}$, ID $0.25 \mathrm{~mm}$, t $0.25 \mu \mathrm{m})$. Initial oven temperature $40^{\circ} \mathrm{C}$ held for $2 \mathrm{~min}$, increased at a ramp rate of $10^{\circ} \mathrm{C} \mathrm{m^{-1 }}$ to $150{ }^{\circ} \mathrm{C}$ and held for $3 \mathrm{~min}$.

\subsection{Post-reaction Catalyst Analysis}

For the INS measurements all sample handling was conducted in an argon filled glove box (MBraun UniLab MB20-G, $\left.\left[\mathrm{H}_{2} \mathrm{O}\right]<1 \mathrm{ppm},\left[\mathrm{O}_{2}\right]<1 \mathrm{ppm}\right)$. The reacted catalyst was removed from the reactor and transferred into aluminium INS flat cells sealed with indium wire. INS spectra were collected with the TOSCA instrument. TOSCA is an indirect geometry instrument with a spectral range of 25 to $4000 \mathrm{~cm}^{-1}$ but is optimal below $2000 \mathrm{~cm}^{-1}$. Some of the reacted catalyst was kept for further analysis using diffuse reflectance infrared Fourier transform spectroscopy (DRIFTS), nitrogen adsorption and temperature programmed oxidation (TPO).

TPO experiments were conducted on the post-reacted ZSM-5 samples using a Hiden CatLab Microreactor integrated with a mass spectrometer and the coke weight percent was verified by thermogravimetric analysis (TGA) using the same procedure (TGA Q50, TA instruments). Approximately, $0.05 \mathrm{~g}$ of reacted catalyst was placed in a quartz reactor and dried at $300{ }^{\circ} \mathrm{C}$ until no water was detected in the mass spectrometer. The TPO was carried out under $20 \% \quad \mathrm{O}_{2} / \mathrm{He}$ with increasing temperature from 40 to $800{ }^{\circ} \mathrm{C}$ at a heating rate of $10{ }^{\circ} \mathrm{C} \mathrm{min}^{-1}$. TGA was completed in the same way, however, air was used instead of the $\mathrm{O}_{2} / \mathrm{He}$ mixture.

Surface area analysis was completed using a Quantachrome Quadrasorb EVO/Si gas adsorption instrument. $0.15 \mathrm{~g}$ of sample was placed in a $9 \mathrm{~mm}$ quartz sample tube and was degassed at $<20 \mathrm{mTorr}$ at $200{ }^{\circ} \mathrm{C}$ for $20 \mathrm{~h}$. The weight of the sample was recorded before being mounted on the Quadrasorb instrument. The Brunauer-Emmett-Teller (BET) equation was used to calculate the surface area in the pressure range $\mathrm{P} / \mathrm{P}_{0}$ of $0.02-0.04$. The micropore volume was calculated from the t-plot curve using the thickness range between 5 and $6.9 \AA$. Adsorption isotherm analysis was completed using the QuadraWin software.

DRIFTS spectra were collected using an Agilent Carey 680 FTIR spectrometer equipped with a Harrick Praying Mantis accessory. Catalyst samples were loaded under argon into the Harrick Praying Mantis high temperature in situ cell fitted with $\mathrm{ZnSe}$ windows. It was then heated in flowing nitrogen $\left(50 \mathrm{~mL} \mathrm{~min}{ }^{-1}\right)$ at a ramp rate of $10{ }^{\circ} \mathrm{C} \min ^{-1}$ to $350{ }^{\circ} \mathrm{C}$ and held at $350{ }^{\circ} \mathrm{C}$ for $30 \mathrm{~min}$. Spectra were collected with 64 scans at $4 \mathrm{~cm}^{-1}$ resolution using a liquid nitrogen cooled MCT detector. 


\section{Results}

\subsection{Reaction Monitoring}

Figure 1 shows the product profiles versus time on stream for (a) methanol alone, (b) methanol:MeOAc 7:3, (c) methanol:MeOAc 4:6 and (d) MeOAc alone. The mass spectrometric analysis is complicated by the contributions from fragmentation of other species but, nonetheless, a number of trends can be identified. For methanol alone, the formation of ethene, propene and aromatic products remains effectively constant over the $6 \mathrm{~h}$ run time. Although there is some increase in the amount of unreacted methanol and DME over this time period, the overall conversion of methanol remains high $(>90 \%)$. Figure 2 plots the methanol and MeOAc conversions versus time for the different reactant compositions tested (conversions were calculated from comparison with mass spectral peak
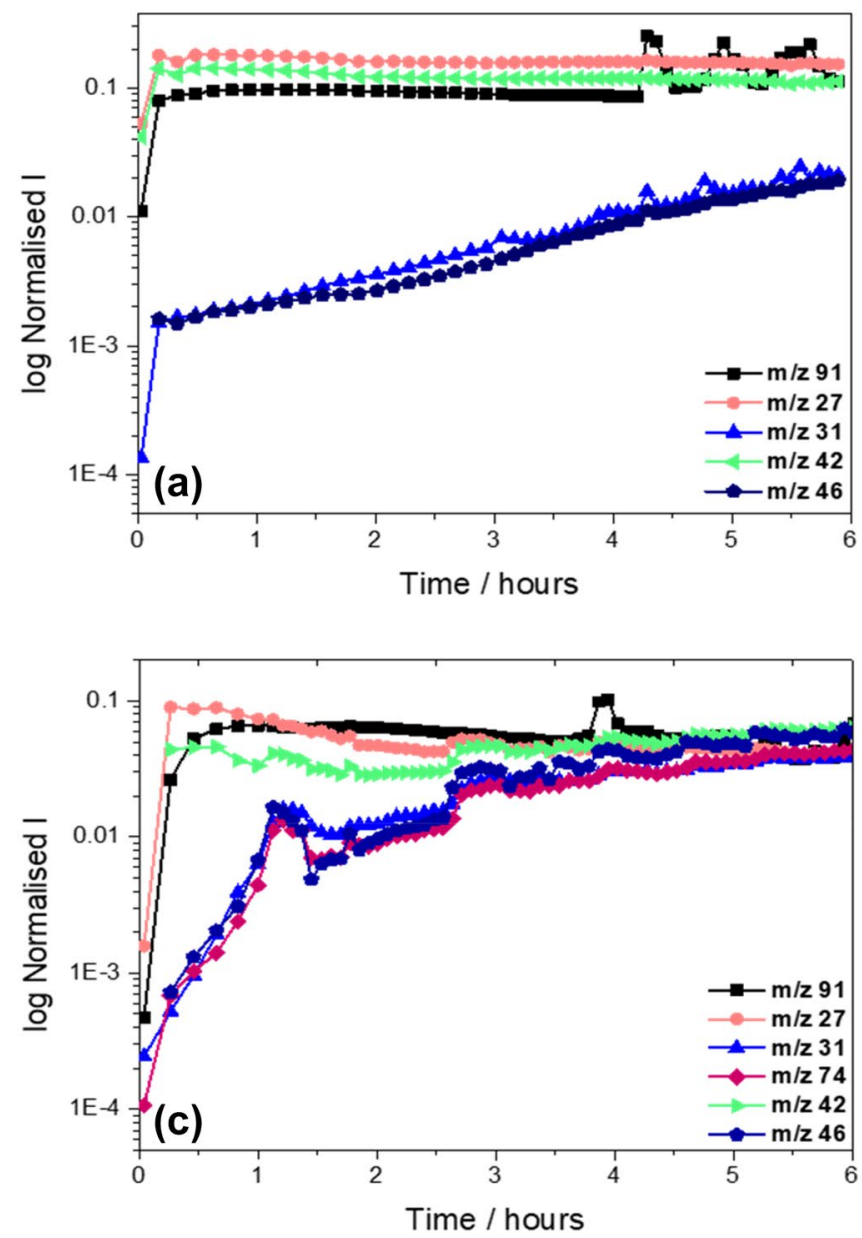

Fig. 1 Mass spectral analysis of reactor exit gases during $\mathrm{MeOH} /$ $\mathrm{MeOAc}$ conversion at $350{ }^{\circ} \mathrm{C}$. a $0 \% \mathrm{MeOAc}$, b 30\% MeOAc, c $60 \%$ $\mathrm{MeOAc}$ and d $100 \%$ MeOAc. m/z 91 (־) signifies the tropylium intensities measured at time $=0$ on bypassing the reactor). Figure $1 \mathrm{~b}$ shows the addition of $30 \% \mathrm{MeOAc}$ leads to a proportionally greater degree of aromatic products, whilst Fig. 2 shows both $\mathrm{MeOH}$ and MeOAc conversions to remain high. Over the range 0-30\% MeOAc content, Fig. 2a shows methanol conversion to be slightly improved in increasing MeOAc; for example at $5 \mathrm{~h}$ T-o-S $10 \%$ and $30 \%$ MeOAc return $\mathrm{X}_{\mathrm{MeOH}}$ values of $99.0 \%$ and $99.9 \%$ respectively, compared to a value of $98.0 \%$ for a pure methanol feed. These small shifts in methanol conversion may reflect changes in the formation of the hydrocarbon pool on increasing presence of the ester.

At $60 \%$ MeOAc Fig. 2 shows a noticeable deactivation to occur. The methanol conversion falls steadily throughout the run and, although aromatic production continues (Fig. 1c), the apparent continued production of ethene and propene is largely due to the contributions to $\mathrm{m} / \mathrm{z}=42$ and 27 from fragmentation of unreacted MeOAc. For a pure MeOAc feedstream, Fig. 1d shows the aromatic signal to steadily
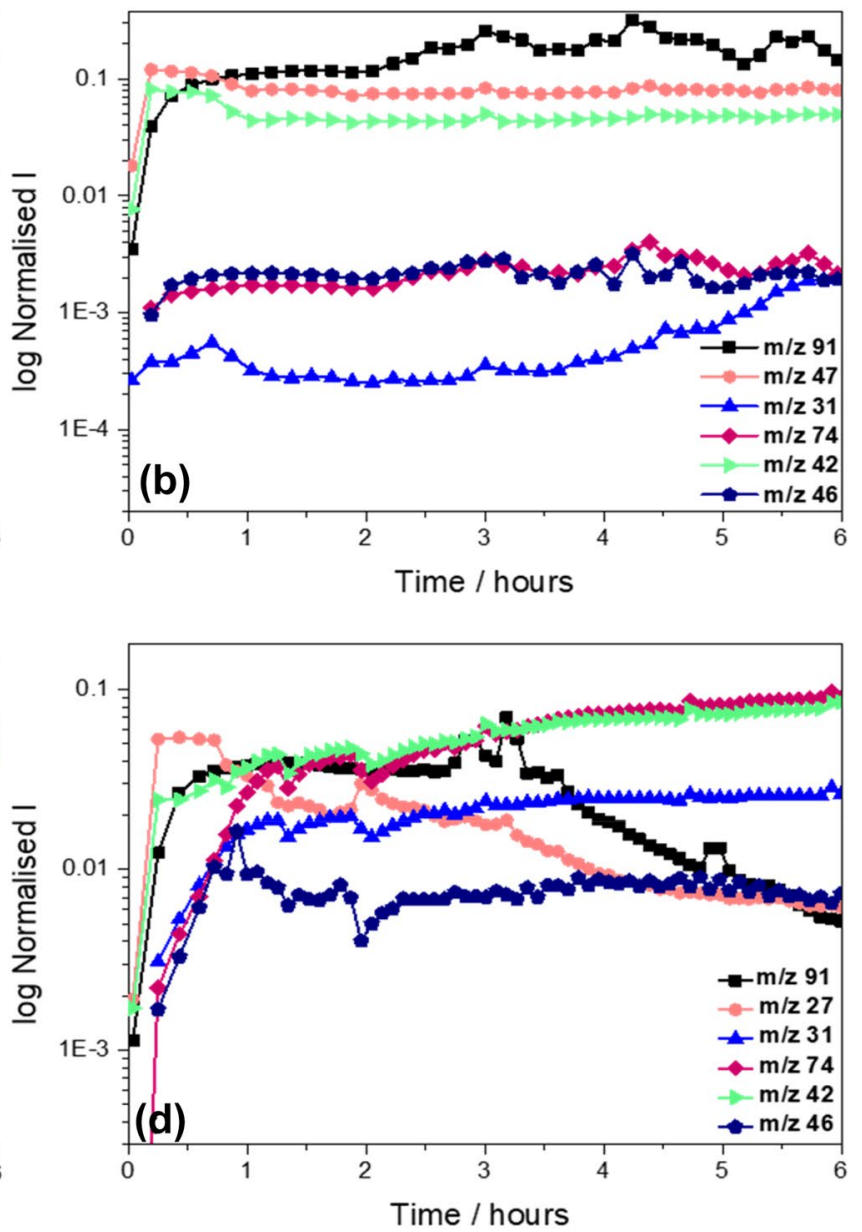

ion indicating aromatics. $\mathrm{m} / \mathrm{z} 74(\multimap-)$ signifies methyl acetate, $\mathrm{m} / \mathrm{z}$ $46(\multimap)$ signifies DME, $\mathrm{m} / \mathrm{z} 42(\longrightarrow)$ signifies propene, $\mathrm{m} / \mathrm{z} 31$ $(\multimap-)$ signifies methanol and $\mathrm{m} / \mathrm{z} 27(\multimap)$ signifies ethene 

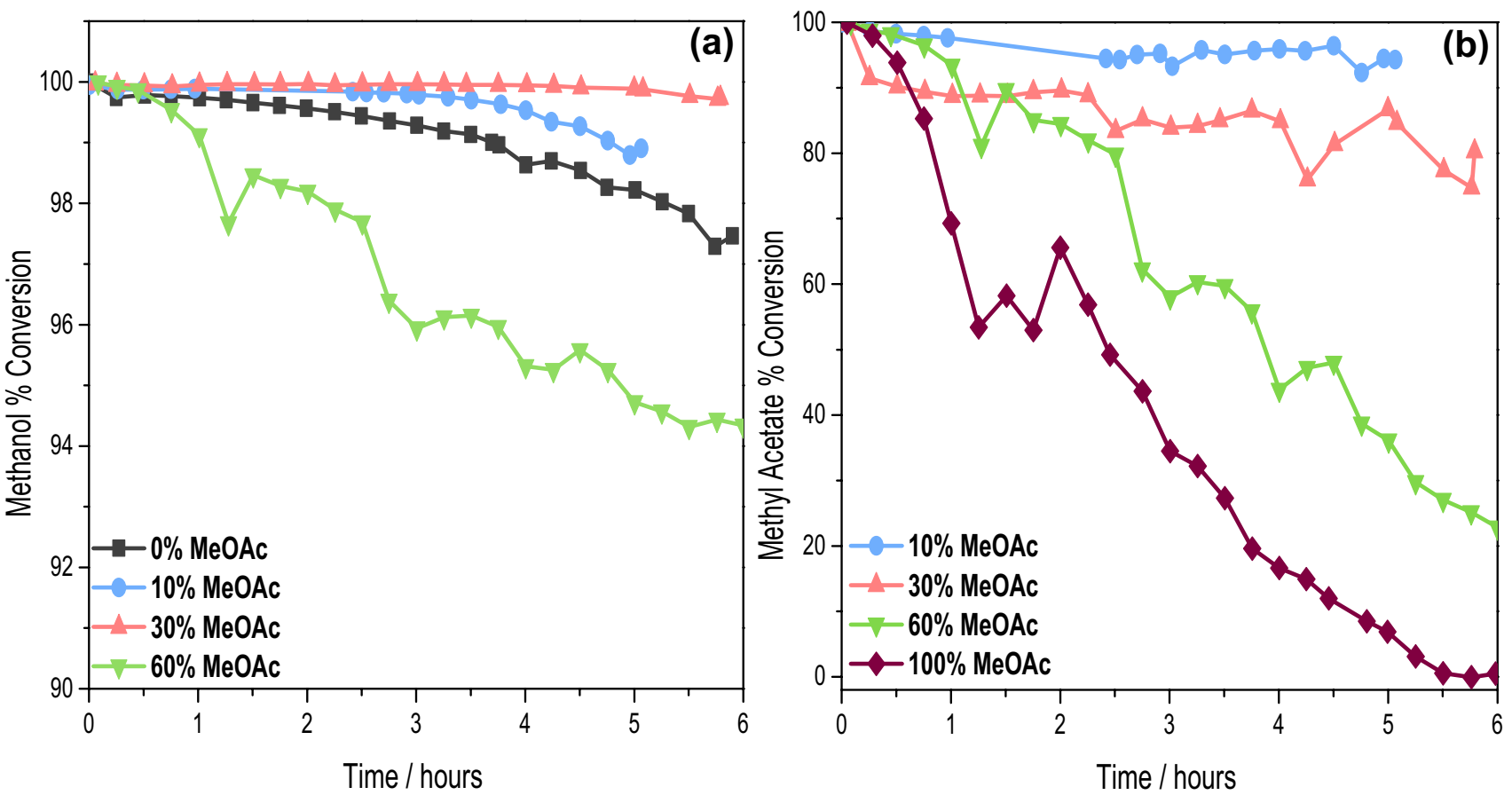

Fig. 2 Methanol (a) and methyl acetate (b) percentage conversion versus time on stream at $350{ }^{\circ} \mathrm{C}$

decline after $\sim 3 \mathrm{~h}$ time-on-stream. There is also a significant increase in the methanol signal, suggesting that hydrolysis of MeOAc may be occurring.

Figure 3 shows GC-MS analysis of the liquid products retained in the reactor catchpot (total product after $6 \mathrm{~h}$ on stream). For pure $\mathrm{MeOAc}$ as the reactant, acetic acid is the major liquid product. In all of the reactions, the hydrocarbon products comprise a mixture of xylenes, tri-methylbenzenes, tetra-methylbenzenes and substituted naphthalenes. These products are still present but at much lower levels when pure $\mathrm{MeOAc}$ was the reactant.

The conversion of MeOAc over SAPO-34 catalysts is reported to give an initial product distribution similar to that formed from methanol, although the production of alkenes falls after only $10 \mathrm{~min}$ on stream at $400{ }^{\circ} \mathrm{C}$ [17]. We are not aware of any comparable study of $\mathrm{MeOAc}$ conversion over
Fig. 3 Catch-pot analysis via GC-MS of liquid products accumulated during $6 \mathrm{~h}$ on stream at $350{ }^{\circ} \mathrm{C}$

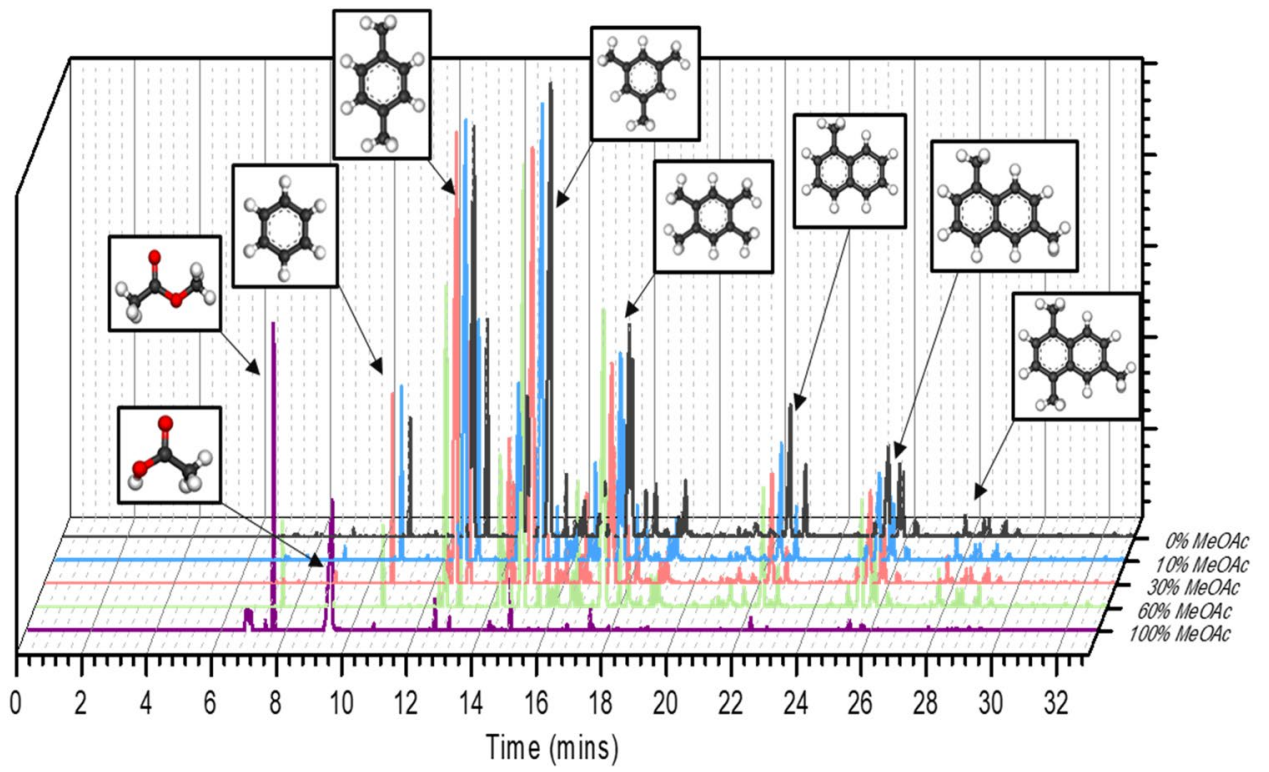


Table 1 Coke content and nitrogen sorption data for the used catalysts

\begin{tabular}{llll}
\hline Reaction feed & $\begin{array}{l}\text { Coke con- } \\
\text { tent }(\mathrm{wt} \%)\end{array}$ & $\begin{array}{l}\text { BET surface } \\
\text { area }\left(\mathrm{m}^{2} \mathrm{~g}^{-1}\right)\end{array}$ & $\begin{array}{l}\text { Micropore } \\
\text { volume }\left(\mathrm{cm}^{3}\right. \\
\left.\mathrm{g}^{-1}\right)\end{array}$ \\
\hline Fresh ZSM-5 [15] & 0 & 387 & 0.148 \\
$0 \% \mathrm{MeOAc}$ & 2.53 & 302 & 0.112 \\
$10 \% \mathrm{MeOAc}$ & 2.81 & 327 & 0.121 \\
$30 \% \mathrm{MeOAc}$ & 7.55 & 155 & 0.054 \\
$60 \% \mathrm{MeOAc}$ & 9.33 & 40.6 & 0.009 \\
$100 \% \mathrm{MeOAc}$ & 9.76 & 22.1 & 0.003 \\
\hline
\end{tabular}

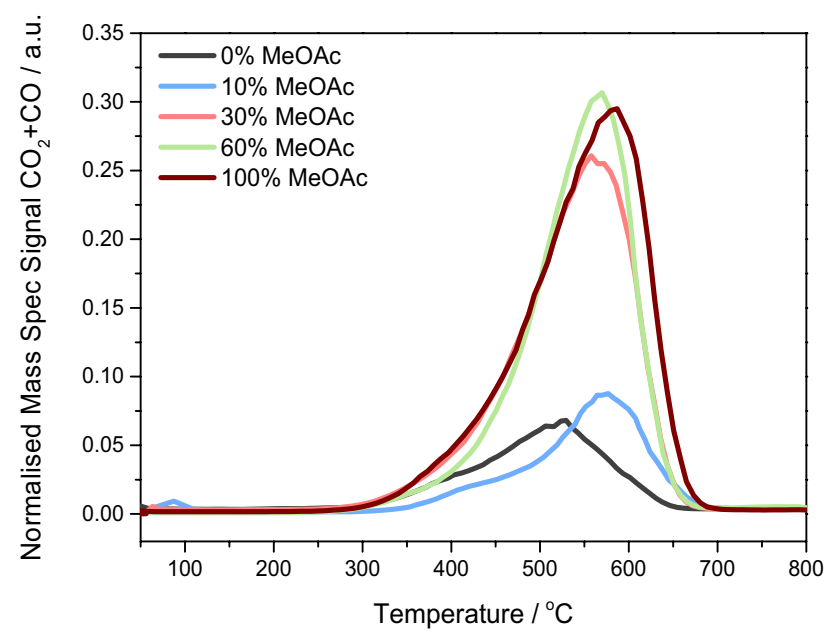

Fig. 4 TPO profiles of the reacted ZSM-5 zeolites

HZSM-5, although we note that coupling of $\mathrm{CO}$ and methanol over HZSM-5 is reported to form aromatic products, presumably via MeOAc [18]. The results presented above suggest that the major role of MeOAc is to promote catalyst deactivation. Accordingly, we examined the used catalysts from the above reactions in more detail.

\subsection{Post-reaction Catalyst Characterisation}

Consistent with the suggested role of MeOAc in promoting catalyst deactivation, the coke content of the used catalysts increased with increasing MeOAc content of the reaction feed, as shown in Table 1. It is noted that this systematic trend contrasts with the small and somewhat anomalous methanol conversion trends observed in Fig. 2a. There is also a corresponding loss of surface area, principally micropore volume, which correlates with the increasing coke content.

These data are consistent with earlier reports that initial coke formation in methanol conversion over HZSM-5 occurs within the micropores of the zeolites [19]. Temperatureprogrammed oxidation measurements reveal that addition of $\mathrm{MeOAc}$ to the reaction feed causes some change in the nature of the coke species. (Fig. 4).

There is a significant shift to higher temperature in the peak maximum in the TPO profile of the used catalysts when MeOAc is added to the feed, from $\sim 520$ to $580{ }^{\circ} \mathrm{C}$. The shift being observed even when $10 \% \mathrm{MeOAc}$ is added to the methanol feed. This suggests that in the presence of $\mathrm{MeOAc}$ the coke deposits have a lower $\mathrm{H}: \mathrm{C}$ ratio than that formed from methanol alone, although there is no evidence for the presence of "hard" or graphitic coke [20] even with a pure $\mathrm{MeOAc}$ feed at $350{ }^{\circ} \mathrm{C}$. The peak shift is consistent with an increased presence of aromatics when methyl acetate is added to the methanol feed.

Figure 5 shows DRIFTS spectra of the used catalysts in the $4000-2200 \mathrm{~cm}^{-1}$ region, in all cases recorded at $350{ }^{\circ} \mathrm{C}$ in flowing helium. The blank zeolite dehydrated at $350{ }^{\circ} \mathrm{C}$ shows two characteristic $\nu(\mathrm{OH})$ bands at 3735 and $3596 \mathrm{~cm}^{-1}$ assigned respectively to $\mathrm{SiOH}$ groups on the external surface or in defects and to $\mathrm{Si}(\mathrm{OH}) \mathrm{Al}$ Brønsted acid sites [21, 22]. An additional weak shoulder at $3650 \mathrm{~cm}^{-1}$ is due to extra-framework $\mathrm{AlOH}$ groups $[23,24]$. The used catalysts all show attenuation of the Brønsted acid band, which becomes more attenuated as the MeOAc content of the feed increases. At higher $\mathrm{MeOAc}$ concentrations the silanol and extra-framework $\mathrm{AlOH}$ bands are also attenuated. The attenuation of the Brønsted acid sites was seen previously in catalysts used for methanol conversion at $350{ }^{\circ} \mathrm{C}$ for 3 days [13], consistent with coke formation at the acid sites. Attenuation of the silanol and extra-framework $\mathrm{AlOH}$ sites is associated specifically with the presence of MeOAc.

In the $\nu(\mathrm{CH})$ region the four bands appearing at 3121, 2971,2926 and $2869 \mathrm{~cm}^{-1}$ closely resemble those reported by Suwardiyanto et al. [13] and assigned to methylated aromatic hydrocarbon species trapped in the zeolite pores. The intensities of these bands increase with $\mathrm{MeOAc}$ content of the feed, as does the coke content, but from this region of the infrared spectrum we cannot identify any differences in the nature of the coke species formed from methanol versus MeOAc. Accordingly, we turned to INS spectroscopy to observe the lower frequency vibrational spectra.

\subsection{Inelastic Neutron Scattering}

Figure 6 shows INS spectra of the blank zeolite, the zeolite containing $\mathrm{MeOAc}$ adsorbed at room temperature, and a sample of pure $\mathrm{MeOAc}$. The spectra are normalised with respect to the weight of the sample. The dosed MeOAc on ZSM-5 shows that the MeOAc remains intact on the ZSM-5 with all the major peaks distinguishable. The peaks become broadened and less intense which could be attributed to the confinement effects of the MeOAc inside the zeolite structure. The blank ZSM-5 spectrum is shown as a reference, showing that the zeolite contribution to the spectra is 
Fig. 5 DRIFTS Spectra of the reacted samples. Spectra were normalised with respect to the zeolite framework peaks at $1864 \mathrm{~cm}^{-1}$ and $1972 \mathrm{~cm}^{-1}$

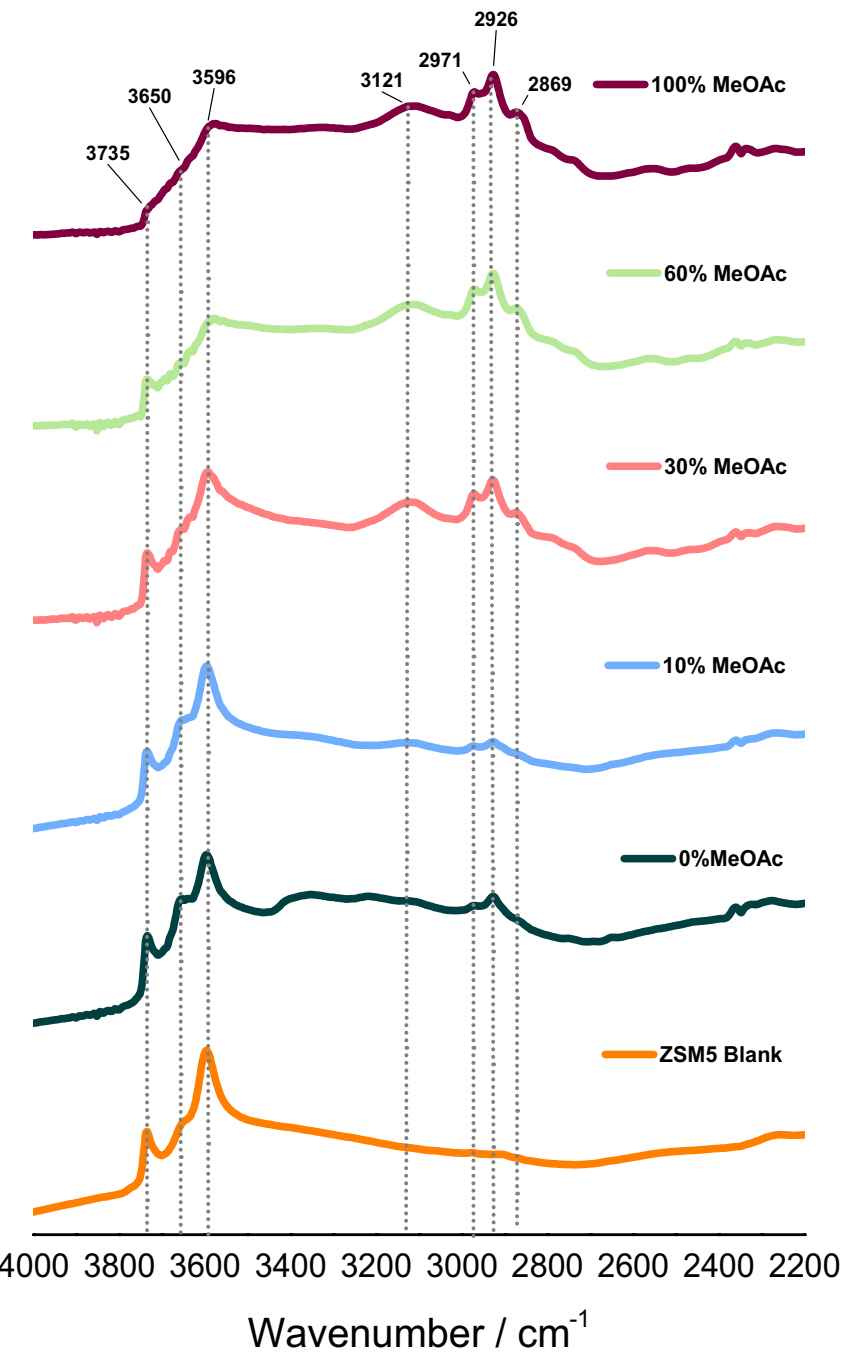

minimal (and emphasising the advantage of INS for studying this region of the spectrum).

Figure 7 shows spectra recorded over the same frequency range for the used catalyst samples. As with the infrared spectra in Fig. 5, the intensities of the bands due to hydrocarbon coke species increase with increasing MeOAc content in the feed. This trend additionally reflects that observed for retained coke content (Table 1). No evidence of features attributable to surface bound methyl acetate entities is apparent in either the IR or INS spectra.

Interestingly, the spectra measured from catalysts exposed to $30 \%$ or more $\mathrm{MeOAc}$ resemble those previously reported for HZSM-5 zeolite catalysts reacted with dimethylether at $350{ }^{\circ} \mathrm{C}$ [15] and importantly have no correspondence to the spectrum of adsorbed MeOAc (Fig. 6). For example, the doublet at 1370 and $1456 \mathrm{~cm}^{-1}$ in Fig. 7 is respectively assigned to $\mathrm{CH}_{3}$ symmetric and asymmetric bending modes of methyl groups attached to aromatic rings and both features are present in all of the spectra except that of the $0 \% \mathrm{MeOAc}$ catalyst. A band at $1186 \mathrm{~cm}^{-1}$ is present
Fig. 6 INS spectra of the blank zeolite (black), methyl acetate (orange) and methyl acetate exposed to ZSM-5 at ambient temperature (grey) 


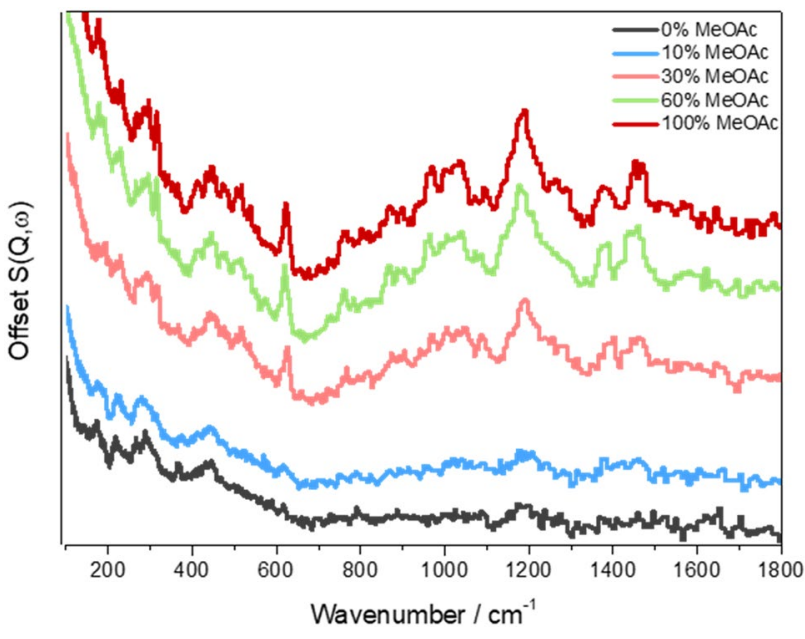

Fig. 7 INS spectra of ZSM-5 samples reacted at $350{ }^{\circ} \mathrm{C}$ for $6 \mathrm{~h}$ with a feed of $0 \%$ MeOAc, $10 \%$ MeOAc, 30\% MeOAc, 60\% MeOAc and $100 \% \mathrm{MeOAc}$

in all spectra, and appears to grow together with the 1370 , $1456 \mathrm{~cm}^{-1}$ doublet, suggesting it is associated with the same species. Likewise, the lower frequency bands are similar to those seen with dimethylether as the reactant [15]. Some differences in relative intensity are noted: bands between 800 and $1000 \mathrm{~cm}^{-1}$ are assigned to aromatic $\mathrm{CH}$ out-of-plane bending modes which are less intense in Fig. 7 relative to the $1033 \mathrm{~cm}^{-1}$ band due to $\mathrm{CH}_{3}$ rocking modes compared with the spectra of the dimethylether catalysts [15]. We attribute these differences to a greater degree of methylation of the aromatic rings in the presence of MeOAc. Highly methylated aromatics have been linked with ZSM-5 deactivation $[19,25]$, which could explain why the increase in MeOAc has also nudged the catalyst in to a deactivation stage earlier than is seen with either methanol or DME. This enhanced extent of methylation in the adsorbed aromatic hydrocarbons appears to be the only significant difference in the INS spectra between the coke deposits formed in the presence and absence of MeOAc.

\section{Discussion}

Methyl acetate has been included in the methanol feedstream and its role in MTH chemistry over HZSM-5 considered. Methyl acetate additions over the range 10-100\% are seen to modify the product distribution of low molecular weight olefins plus aromatic compounds and perturb methanol conversion. The ester appears to accelerate catalyst deactivation by enhancing the formation of methylated aromatic coke compounds that block active sites within the zeolite. Müller et al. [26] have suggested that initial coke formation in ZSM-5 is enhanced by the presence of oxygenated compounds, but the vibrational spectroscopic data show no evidence for the presence of anything other than methylated aromatics in the used catalysts studied here, and the TPO data show no sign of the Type I coke observed in reference [26]. One possible origin for the deactivation trends observed could be that the presence of methyl acetate in the feedstream leads to a constrained supply of water molecules in the reaction zone (formed as a product in the dimerization of methanol to produce dimethyl ether), which would otherwise facilitate re-generation of the active sites (Brønsted acid sites) [15].

Acknowledgements Johnson Matthey plc and the EPSRC are thanked for postgraduate student support (A.P.H., A.Z.) via the Industrial CASE scheme (EP/P510506/1). Johnson Matthey plc is additionally thanked for provision of the ZSM-5 catalyst. The Science and Technology Facilities Council is thanked for the provision of neutron beam time (RB1820116, https://doi.org/10.5286/isis.e.97999822). The resources and support provided by the UK Catalysis Hub via Membership of the UK Catalysis Hub Consortium and funded by EPSRC (Grants EP/ K014706/1, EP/K014668/1, EP/ K014854/1, EP/K014714/1, and EP/ M013219/1) are gratefully acknowledged.

Data Availability The datasets generated during and/or analysed during the current study are available from the corresponding author on reasonable request.

\section{Compliance with Ethical Standards}

Conflicts of interest The authors have no conflicts of interest.

Research Invloving Human and/or Animal Rights There were no human or animal subjects involved in this research.

Open Access This article is licensed under a Creative Commons Attribution 4.0 International License, which permits use, sharing, adaptation, distribution and reproduction in any medium or format, as long as you give appropriate credit to the original author(s) and the source, provide a link to the Creative Commons licence, and indicate if changes were made. The images or other third party material in this article are included in the article's Creative Commons licence, unless indicated otherwise in a credit line to the material. If material is not included in the article's Creative Commons licence and your intended use is not permitted by statutory regulation or exceeds the permitted use, you will need to obtain permission directly from the copyright holder. To view a copy of this licence, visit http://creativecommons.org/licenses/by/4.0/.

\section{References}

1. Chang CD (1983) Hydrocarbons from methanol. Catal Rev 25:1-118

2. Olsbye U, Svelle S, Lillerud KP et al (2015) The formation and degradation of active species during methanol conversion over protonated zeotype catalysts. Chem Soc Rev 44:7155-7176

3. Hemelsoet K, Van der Mynsbrugge J, De Wispelaere K et al (2013) Unraveling the reaction mechanisms governing methanolto-olefins catalysis by theory and experiment. ChemPhysChem $14: 1526-1545$ 
4. Yarulina I, Chowdhury AD, Meirer F et al (2018) Recent trends and fundamental insights in the methanol-to-hydrocarbons process. Nat Catal 1:398-411

5. Liu Y, Müller S, Berger D et al (2016) Catalytic mechanisms formation mechanism of the first carbon-carbon bond and the first olefin in the methanol conversion into hydrocarbons. Angew Chem Int Ed 55:5723-5726

6. Chowdhury AD, Houben K, Whiting GT et al (2016) Initial carbon-carbon bond formation during the early stages of the methanol-to-olefin process proven by zeolite-trapped acetate and methyl acetate. Angew Chem Int Ed 55:15840-15845

7. Cheung P, Bhan A, Sunley GJ, Iglesia E (2006) Selective carbonylation of dimethyl ether to methyl acetate catalyzed by acidic zeolites. Angew Chem Int Ed 45:1617-1620

8. Wang S, Li S, Zhang L et al (2018) Mechanistic insights into the catalytic role of various acid sites on ZSM-5 zeolite in the carbonylation of methanol and dimethyl ether $\uparrow$. Catal Sci Technol $8: 3193$

9. Haas A, Hauber C, Kirchmann M (2019) Time-resolved product analysis of dimethyl ether-to-olefins conversion on SAPO-34. https://doi.org/10.1021/acscatal.9b00765

10. Anderson MW, Klinowski J (1989) Direct observation of shape selectivity in zeolite ZSM-5 by magic-angle-spinning NMR. Nature 339:200-203

11. Jiang Y, Hunger M, Wang W (2006) On the reactivity of surface methoxy species in acidic zeolites. https://doi.org/10.1021/JA061 $018 \mathrm{Y}$

12. Parker SF, Lennon D, Albers PW (2011) Vibrational spectroscopy with neutrons: a review of new directions. Appl Spectrosc 65:1325-1341

13. Suwardiyanto, Howe RF, Catlow RCA et al (2017) An assessment of hydrocarbon species in the methanol-to-hydrocarbon reaction over a ZSM-5 catalyst. Faraday Discuss 197:447

14. Howe RF, McGregor J, Parker SF et al (2016) Application of inelastic neutron scattering to the methanol-to-gasoline reaction over a ZSM-5 catalyst. Catal Lett 146:1242-1248

15. Zachariou A, Hawkins A, Lennon D et al (2019) Investigation of ZSM-5 catalysts for dimethylether conversion using inelastic neutron scattering. Appl Catal A 569:1-7

16. Warringham R, Bellaire D, Parker SF et al (2014) Sample environment issues relevant to the acquisition of inelastic neutron scattering measurements of heterogeneous catalyst samples. J Phys Conf Ser 554:012005

17. Chowdhury AD, Paioni AL, Houben K et al (2018) Bridging the gap between the direct and hydrocarbon pool mechanisms of the methanol-to-hydrocarbons process. Angew Chem Int Ed 57:8095-8099

18. Chen Z, Ni Y, Zhi Y et al (2018) Coupling of methanol and carbon monoxide over H-ZSM-5 to form aromatics. Angew Chem Int Ed $57: 12549-12553$

19. Bibby DM, Howe RF, Mclellan GD (1992) Coke formation in high-silica zeolites. Appl Catal A 93:1-34

20. Choudhary VR, Devadas P, Sansare SD, Guisnet M (1997) Temperature programmed oxidation of coked $\mathrm{H}$-gallosilicate (MFI) propane aromatization catalyst: influence of catalyst composition and pretreatment parameters. J Catal 166:236-243

21. Jacobs PA, Von Ballmoos R (1982) Framework hydroxyl groups of H-ZSM-5 zeolites. J Phys Chem 86:3050-3052

22. Vedrine JC, Auroux A, Coudurier G (1984) Combined physical techniques in the characterization of zeolite ZSM-5 and ZSM-11 acidity and basicity. In: ACS symposium series, pp 254-273

23. Kubelková L, Nováková J, Nedomová K (1990) Reactivity of surface species on zeolites in methanol conversion. J Catal 124:441-450

24. Campbell SM, Bibby DM, Coddington JM et al (1996) Dealumination of HZSM-5 zeolites: I. Calcination and hydrothermal treatment. J Catal 161:338-349

25. Rojo-Gama D, Nielsen M, Wragg DS et al (2017) A straightforward descriptor for the deactivation of zeolite catalyst H-ZSM-5. ACS Catal 7:8235-8246

26. Müller S, Liu Y, Vishnuvarthan M et al (2015) Coke formation and deactivation pathways on H-ZSM-5 in the conversion of methanol to olefins. J Catal 325:48-59

Publisher's Note Springer Nature remains neutral with regard to jurisdictional claims in published maps and institutional affiliations. 